The Sumner and SEP $\angle 01 \mathrm{y}$,
Laura Foster Library
Center for Research on Economic and Social Theory
CREST Working Paper

Michelle J. White

July 29, 1987

Number $87--3$

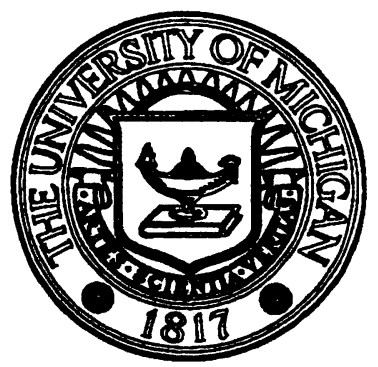

DEPARTMENT OF ECONOMICS University of Michigan Ann Arbor, Michigan 48109 



\title{
Contract Breach and Contract Discharge due to Impossibility: A Unified Theory
}

by

\author{
Michelle J. White* \\ University of Michigan
}

July 29, 1987

Address. Law School, University of Michigan, Ann Arbor, MI 48109-1216 



\section{Contract Breach and Contract Discharge due to Impossibility: A Unified Theory \\ Michelle J. White*}

\section{Introduction}

The literature on contract remedies treats breach of contract and discharge of contract duc to impossibility, impracticability, or frustration as completely separate problems calling for completely different solutions. Breach of contract has been analyzed as a problem in how to use damage remedies as prices which will encourage economically efficient behavior by the breaching party. Discharge of contract, in contrast, has been analyzed as a question of whether or not to excuse the non-performing party without imposing any penalty at all, with the answer often depending on which party is the superior risk bearer. I argue in this paper that both problems should be analyzed using the theory of contract breach. Under the theory, it would not be necessary for courts to decide whether a case involving an unperformed contract should be treated as a breach of contract or should be discharged. Instead, all cases involving unperformed contracts would be treated as breach of contract cases. The courts would focus their efforts on deciding the best damage remedy, rather than having to decide whether a contract has been breached or not. Damages would always be levied on the non-performing party, although their level would depend on circumstances specific to each case. In a few special cases, damages would equal zero, but I argue that these would be rare.

The economic analysis of breach of contract is concerned with achieving economic efficiency in three separate dimensions. These are (A) giving the promisor to a contract an incentive to perform as promised if and only if doing so increases economic efficiency, (B) giving the promisee to a contract an incentive to make reliance expenditures only if they are economically worthwhile given the possibility that the contract may not be performed, and (C) minimizing the costs of risk bearing by both parties to the contract. ${ }^{1}$

Professor of Economics and Visiting Professor of Law, University of Michigan. 
(The contract is assumed to be between a seller, who agrees to perform some service or provide some good, and the buyer, who agrees to pay for the good or service.) In the analysis of contract breach, various damage measures are analyzed to determine how well they perform on each of the three criteria. ${ }^{2}$

The economic analysis of whether and when unperformed contracts should be discharged is due to Richard Posner and Andrew Rosenfield (cited hereinafter as $\mathbf{P}$ and $\mathrm{R}$ ). ${ }^{3}$ Their analysis focuses on the question of risk bearing. They argue that the key question is which party to the contract is the "superior risk bearer," i.e., which is able to bear the risk of the contract not being performed more cheaply. If the promisor is the superior risk bearer, then $P$ and $R$ argue that the case should be treated under the doctrine of breach of contract and the promisor should pay damages. If the promisee is the superior risk bearer, then $P$ and $R$ argue that the contract should be discharged with no damages levied on the promisor.

Thus $\mathrm{P}$ and $\mathrm{R}$ make efficient risk bearing the focus of their theory of contract discharge. It is also objective (C) of the economic theory of contract breach. However, in the theory of contract breach, it turns out always to be economically efficient for the promisor to pay damages if the contract is not performed (although the efficient level of damages might turn out to be zero in some special cases). Applying the theory of remedies in cases of contract breach to the problem of contract discharge, I argue that damages should be levied whenever the promisor fails to complete a contract. In other words, unperformed contracts should never be discharged.

The plan of the paper is as follows. In section 2, I review relevant parts of the economic theory of damage remedies in breach of contract cases, ignoring the possibility that the contract might be discharged. In section 3, I review $P$ and R's analysis of contract discharge and then combine it with the previous analysis of efficient damage remedics in cases of contract breach. This is shown to result in a unified theory which treats all unperformed contracts according to the theory of breach of contract. In section 4, I apply the analysis to several factual situations suggested by cases of contract discharge. Section 5 is the conclusion. 


\section{Risk Bearing and Breach of Contract Remedies}

In many breach of contract cases, the economic analysis focuses on determining a damage remedy which functions as a price for not performing the contract. This is criterion (A) of the three objectives mentioned above. Ideally it should give the promisor an incentive to perform the contract if doing so increases economic efficiency, i.e., causes goods or scrvices to be produced which have higher value than those the parties would produce if the contract were not performed. Conversely, the remedy should give the promisor an incentive not to perform the contract if doing so would reduce economic efficiency. The expectation damage remedy requires that the promisor compensate the promisee for the lattcr's loss in profits when the contract is not performed. It therefore gives the promisor an incentive to breach only when its own losses from performing the contract exceed the profits that the promisee would make were the contract performed. Under these circumstances, there would be a net loss in economic efficiency from performing the contract. The promisor has an incentive to perform the contract even when it makes losses, so long as its losses from performing are less than the promisee's profits. Thus the expectation damage remedy gives the promisor an incentive to perform the contract when doing so would be economically efficient and not otherwise.

In other cases involving breach of contract, questions of whether the contract should have bcen performed or not are not the primary focus. Instead, what is the primarily at issue is which party is the more economically efficient bearer of risk, objective (C) of the three efficiency criteria. ${ }^{4}$ Assume that the risk of whether the contract is performed or not must be absorbed by one of the two parties to the contract, i.e., there is no outside insurer. Also assume that both parties to the contract are either risk neutral or risk averse. ${ }^{5} \mathrm{By}$ setting the damage remedy for breach of contract at different levels, the risk associated with the contract not being performed can be absorbed entirely by the promisor, or can be transferred entirely to the promisee, or can be split in some proportion between the two parties. When other efficiency considerations are not relevant (ruling out criterion (A)), economic efficiency requires that the risk be absorbed by whichever party can bear it more cheaply. But when the probability of the contract being performed or not is affected by the seller's behavior, then criterion (A) is also relevant. In that case, economic efficiency 
requires that efficient risk bearing and efficient incentives for the promisor to perform or breach the contract be balanced against each other.

These considerations can be illustrated with an example which involves both breach incentives and risk bearing considerations. Suppose a seller agrees to produce and sell custom-made widgets to a buyer for a price of $\boldsymbol{P}$ per unit. Some portion of the contract price, $a$, is paid in advance, where $a$ must be between zero (no payment in advance) and one (full payment in advance). The actual dollar amount paid in advance is thus $a P$. The remainder of the contract price, $(1-a) P$, is assumed to be paid as soon as the contract is performed. The seller's normal cost of production is $C$ per unit. All of the seller's costs are assumed to be variable costs. ${ }^{6}$ The buyer spends $S$ per unit on other materials which are only useful if the widgets are delivered. Assuming that the contract is performed, the buyer will re-sell the widgets for $R$ per unit and will therefore make a profit of $R-P-S .^{7}$ Since the contract is normally profitable for both parties, I assume that $R>P+S$ and that $P>C$. However, due to rioting in South Africa, the price of titanium, an input into widget production, may rise. This would cause the cost of producing widgets to rise from $C$ to $C^{\prime}$ per unit. Assume that the cost increase, $C-C^{\prime}$, exceeds the seller's normal profit from producing widgets, or $C^{\prime}-C>P-C$. As a result, the seller would make a loss by performing the contract when the price rise occurs. By assumption, if the contract is not performed, the buyer has nothing to re-sell and loses the revenue, $R$, that would otherwise have been earned. ${ }^{8}$

The efficiency considerations with respect to criterion (A) are as follows. Assuming that the cost increase has occurred, it is economically efficient to perform the contract when the profits of both buyer and seller together are higher if it is performed than if it is not performed, and not to perform the contract otherwise. Given the cost increasc, if the contract is performed, the seller's profit (actually a loss) will be $P-C^{\prime}$ and the buyer's profit will be $R-P-S$. Their profits together are $R-S-C^{\prime}$. If the contract is not performed, the seller will incur no production costs, so its profit will be $a P$. The buyer's loss will be $-a P-S$. Together their profits will be $-S$. Therefore, it is economically cfficient to perform the contract if $R-S-C^{\prime}>-S$, or if $R>C^{\prime}$. It is economically efficient not to perform it in the opposite case, or if $R<C^{\prime}$. Another way of putting this is that, 
performing the contract is efficient when $R-P>C^{\prime}-P$. A damage remedy which gives the seller efficient incentives to perform or not must cause the seller to perform whenever the buyer's profit exceeds the seller's loss given the higher cost level, and not to perform otherwise.

We now turn to the question of efficient risk bearing, criterion (C). To analyze risk bearing, we need to consider whether the seller and the buyer are each risk neutral or risk avcrse. There are four possible cases: (1) both seller and buyer are risk neutral, (2) the seller is risk neutral and the buyer risk averse, (3) the seller is risk averse and the buyer is risk ncutral, and (4) both are risk averse. Polinsky ${ }^{9}$ analyzed this question and set out what the most efficient damage remedy would be in the various cases.

Case (1), buyer and seller risk neutral. If both buyer and seller are risk neutral, then neither cares about uncertainty per se, each cares only about his/her expected return. Since risk bearing costs are not a consideration, then the damage remedy if the contract is not performed can be set without regard to risk bearing considerations. Therefore the bcst damage remedy is expectation damages, since expectation damages give the seller an incentive to perform the contract when doing so would be economically efficient and not to perform the contract when doing so would waste resources. In our example, if the contract is not performed when costs rise, the seller must pay the buyer damages of $R-(1-a) P$ per unit. Here, the buyer loses $R$ per unit in revenue when the contract is not performed, but saves the amount not paid in advance for the widgets, or $(1-a) P$ per unit. Given these damages, the buyer's profit is $R-P-S$ per unit regardless of whether the contract is performed or not, which preserves the buyer's profit "expectations". The seller will choose to perform the contract or not depending on which alternative yields higher profit. Therefore she will breach when $R-P<C^{\prime}-P$. But this is just the criterion determining when breach of contract is economically efficient. Thus the seller's decision is economically cfficient.

In case (1), the best damage remedy when breach occurs is $R-(1-a) P$, which is a generalized form of expectation damages. To see this, note that in cases where none of the contract price is paid in advance, then $a$ equals zero. Then the efficient damage remedy is $R-P$, which is the buyer's profit per unit. When the entire contract price is paid in 
advance, $a$ equals one and the efficient damage remedy becomes $R$, or the buyer's revenue per unit. $^{10}$

Case (2), seller risk neutral and buyer risk averse. Here the seller does not care about uncertainty per se, but the buyer is made worse off by uncertainty and would be willing to pay some amount to avoid it, i.e., to insure a fixed amount of profit regardless of whether the contract is performed or not. In this case, the seller is the more efficient risk bearer, since the seller is not willing to pay any amount to avoid bearing risk. The seller in effect agrees to sell both widgets and an insurance policy insuring the buyer's profits against the risk of the widgets not being delivered. ${ }^{11}$

In this case, damages equal to $R-(1-a) P$ are again the best damage remedy when the seller does not perform the contract. When damages are $R-(1-a) P$ per unit, the buyer makes the same profit regardless of whether the contract is performed or not and is therefore fully insured. All uncertainty is absorbed by the seller. But since the seller is risk neutral, the seller is the economically efficient risk bearer. Therefore the expectation damages remedy both gives the seller efficient incentives concerning whether or not to perform the contract (criterion (A)) and causes the most efficient risk bearer to bear the risk (criterion (C)).

Case (3), seller risk averse and buyer risk neutral. In this case, the seller prefers not to absorb any risk and is willing to pay to transfer risk to the buyer. The buyer is the efficient risk bearer. The damage remedy therefore must equalize the seller's profit in the normal case when the contract is performed, which is $P-C$, and in the case when the adverse event occurs and the seller does not perform, which is $a P$ minus damages paid. The level of damages which makes these two profit levels equal is $C-(1-a) P$, or the seller's normal production cost minus the amount of the contract price not paid in advance. All uncertainty is therefore absorbed by the buyer. ${ }^{12}$

Thus when the buyer is risk averse and the seller is risk neutral, the damage remedy which satisfies criterion (C) equals $C-(1-a) P$. However, this damage remedy does not in general satisfy criterion (A). Damages of $C-(1-a) P$ are always less than $R-(1-a) P$, the damage remedy which satisfies criterion (A). The level of damages that leads to efficient risk bearing in case (3) therefore can cause sellers to have an incentive to breach contracts when 
performing them would be economically efficient. A damage level closer to $C-(1-a) P$ reduces risk bearing costs in risk case (3), but increases the cost of inefficient breach incentives, while a damage level closer to $R-(1-a) P$ has the opposite effect.

Case (4), both buyer and seller risk averse. In this case both parties are willing to pay some amount to avoid bearing risk. Then the efficient outcome in terms of risk bearing is for them to share the risk of non-performance. For example, if they are both about equally risk averse, then the efficient damage remedy when the contract is not performed would be for the seller to pay damages equal to the midpoint between $R-(1-a) P$ and $C-(1-a) P$, the efficient damage levels in cases (2) and (3). If the buyer is more risk averse than the seller or vice versa, then it would be efficient for them to share the risk, but unequally. Note that as in case (3), the damage remedy that satisfies criterion (C) does not always satisfy criterion (A). If the seller has full or partial control over whether the contract is performed or not, then any damage remedy below $R-(1-a) P$ gives the seller an incentive to breach too often.

An important implication of the analysis is that the only damage remedies which share risk efficiently between the two parties are those which fall between the damage remedies specified in cases (2) and (3), or between $R-(1-a) P$ and $C-(1-a) P$. Within this range, increases or decreases in the damage remedy have the effect of reducing the uncertainty faced by one of the parties at the expense of increasing the uncertainty faced by the other. But any damage remedy outside this range, i.e., greater than $R-(1-a) P$ or less than $C-(1-a) P$, increases the range of outcomes faced by both parties simultaneously and thus increases the total costs of risk bearing. ${ }^{13}$

\section{Risk Bearing and Discharge of Contract}

Now turn to the analysis of whether a contract which the promisor has failed to perform should be discharged by the courts without penalty or found to be breached. $P$ and $R$ propose a test for breach versus discharge which focuses on whether the promisor or the promisee is the superior risk bearer. ${ }^{14}$ When the promisee is the superior risk bearer, they argue that contracts should be discharged without penalty to the promisor. When the promisor is the superior risk bearer, nonperformance should be treated as a breach of 
contract and the promisor should pay damages. We now investigate how $P$ and $R$ 's analysis of contract breach versus discharge fits into our previous analysis of damage remedies in cases of contract breach.

Several points should be clarified. First, $\mathbf{P}$ and R's analysis of whether or not contracts should be discharged focuses on cases in which the promisor's decision whether or not to perform the contract is not an important issue. This is because the event that makes discharge a consideration in their examples is beyond the control of the performing party. Thus the problem of setting damage remedies so as to give promisors efficient incentives concerning whether to perform their contracts or not, our economic efficiency criterion (A), is not the focus of their analysis. ${ }^{15}$ Instead, their focus is on efficient risk bearing, our criterion (C).

Second, the discussion of contract discharge generally is applied in situations in which no outside insurer is involved. Thus the parties to the contract must themselves bear the risk and the consequences of non-performance. Third, P and R's definition of a party to a contract being the "superior risk bearer" embodies the same ideas as our discussion of parties being risk averse or risk neutral. In their terminology, one party to a contract is the superior risk bearer if that party would be willing to provide insurance against the consequences of the contract not being performed for a lower price than the other party. In our terminology, the superior risk bearer is either risk neutral when the other party to the contract is risk averse or else both are risk averse, but the superior risk bearer is less risk averse than the other party. The less risk averse person is always willing to provide insurance more cheaply.

We showed in the previous section that regardless of whether either or both parties to a contract are risk averse or risk neutral, the most efficient outcome is always for the promisor to an unperformed contract to pay damages to the promisee. Thus the analysis of the previous section implies that courts should treat all unperformed contracts as cases of contract breach and should focus on what the best damage remedy would be in the particular case. Courts should not spend effort deciding whether to discharge. unperformed contracts or to hold that they have been breached. Instead they should treat, all cases involving umperformed contracts as breach cases and should focus on whether 
one party to the contract is less risk averse (or the "superior risk bearer") and absorbed the risk of non-performance, or whether both parties are risk averse and they shared the risk of non-performance. Damages for breach of contract should always be levied on the promisor, but the amount of damages should depend on which party absorbed the risk or on whether it was shared. The best remedies from the viewpoint of risk allocation in the four risk cases were shown to be expection damages equal to the $R-(1-a) P$ in risk cases (1) and (2), damages equal to the $C-(1-a) P$ in case (3), and damages between these two extremes in case (4). The best remedy from the viewpoint of providing efficient incentives for performance was shown to be expectation damages, or $R-(1-a) P$.

Suppose now that instead of finding the widget contract in our previous example to have been breached, a court decides instead to discharge the contract, so that the seller is excused from paying damages. We now show that this outcome would cause neither efficient risk bearing to occur except in some special cases (criterion (C)), nor would it set up economically efficient incentives with regard to the seller's decision whether or not to perform the contract (criterion (A)).

To see this, suppose that in the widget example, the contract is discharged when the cost increase occurs. If the contract were discharged, the seller's profit would be $a P$, while the buyer's loss would be $-a P-S$. If no cost increase occurred and the contract were performed, their profits would be $P-C$ and $R-P-S$, respectively. ${ }^{16}$ Thus discharge provides neither party with insurance. Further, in most cases the discharge remedy actually accentuates the total risk faced by both parties. This is because damages of zero are generally outside the risk minimizing range of penalties.

To investigate the implications of discharge further, suppose for the moment that the contract price has been paid entirely in advance, so $a$ equals one. In that case the risk minimizing range of damages extends from a maximum of $R$ in cases (1) and (2) to a minimum of $C$ in case (3), and are between within this range in case (4). The range of efficient damage remedies does not include zero. Regardless of the parties' risk preferences, the level of damages leading to efficient risk bearing must always be positive, and is never zero. Any increase or decrease in the damages within the $C$ to $R$ range has the effect of reducing the uncertainty faced by one party at the expense of increasing the uncertainty 
faced by the other. But any increase or decrease in the level of damages which puts it outside this range, including damages of zero, increases the uncertainty faced by both parties simultaneously. Thus if the contract were discharged, the risk faced by both parties would increase.

Further, discharge in this case would not satisfy criterion (A). This means that in some situations the seller would have an incentive not to perform the contract when performing it would be economically efficient. We showed earlier that if $a=1$, then the seller has economically efficient performance incentives when damages for breach of contract equal $R$ per unit. Any damage level less than $R$ gives the seller an incentive to breach too often. Therefore discharging the seller, which is equivalent to a damage remedy of zero, gives the seller an incentive to breach too often.

Now suppose that none of the contract price was paid in advance. Then $a$ equals zero and the range of damage remedies leading to efficient risk bearing in cases (1) to (4) becomes $C-P$ to $R-P$. While $R-P$ must still be positive, now the lowest damage remedy in the efficient range, $C-P$, must be negative. Thus a negative damage remedy shares risk efficiently when case (3) holds, or when the seller is risk averse and the buyer is risk neutral. The sellers's profit when the contract is performed is $P-C$. When the contract is not performed and none of the contract price has been paid in advance, the only way for the seller to make this level of profit is for the buyer to pay the seller $P-C$, which is equivalent to a negative damage remedy of $C-P$. Or, equivalently, the buyer could pay the seller the contract price $P$ and then the seller return $C$ to the buyer as damages.

The prediction of a negative damage remedy seems counterfactual. It also seems unfair ex post because it amounts to a subsidy being paid to the non-performing party. Probably the reason that negative damage remedies are not observed is that a risk averse seller bargaining with a risk neutral buyer would insist on being paid in advance, because the scller would recognize how difficult it would be to enforce a damage remedy that compensated the seller when the seller failed to perform the contract. Since the size of the efficient damage remedy increases (becomes less negative) as the proportion of the contract price paid in advance increases, we expect that where a negative damage remedy would otherwise occur, the buyer and seller will instead specify in their contract that a high proportion of 
the contract price be in paid in advance. This suggests that in practice, Courts should not conclude that contracting parties fit the assumptions of case (3) unless their contracts provide for most or all of the price to be paid in advance. Thus while the theory predicts that cfficient risk bearing could lead to negative damage remedies in some situations, these are unlikely to be observed.

Note that the damage remedy called for by efficient risk bearing in this case is again lower than the remedy that would give the seller efficient incentives concerning whether to perform the contract. In this case damages of $R-P$ per unit would give the seller efficient performance incentives. The lower damage remedy called for by risk bearing considerations when the seller is risk averse gives the seller an incentive not to perform the contract too frequently.

Suppose now that part but not all of the all of the contract price is paid in advance. Now the risk minimizing range of damages extends from $C-(1-a) P$ to $R-(1-a) P$. Since $C$ must be less than $P$, this damage range includes zero as a possible outcome. Since a zero damage remedy is equivalent to discharge, this suggests that discharge may be consistent with efficient risk bearing in some special cases.

To illustrate the type of special case in which zero damages lead to efficient risk bearing, suppose that the seller is risk averse and the buyer is risk neutral (case (3)). Then the risk minimizing damage remedy is $C-(1-a) P$. This equals zero if the particular value of $a$ chosen by the parties, call it $a_{1}$, satisfies the condition that $a_{1}=\frac{(P-C)}{P} \cdot \frac{(P-C)}{P}$ equals the seller's percent markup over cost. Thus if the seller is risk averse and the buyer risk neutral and if the proportion of the contract price paid in advance equals the seller's percent markup over cost, then discharge would lead to efficient risk bearing. As another example, suppose the buyer and seller are equally risk averse, which puts them in case (4). Then they would agree on a liquidated damage remedy in the middle of the risk minimizing damage range, or $.5(C-(1-a) P)+.5(R-(1-a) P)$. But this damage remedy could equal zero. The condition for it to equal zero is that the particular value of $a$ chosen by the parties, denotes $a_{2}$, satisfy the condition that $a_{2}=\frac{1}{2}\left[\frac{(P-C)}{P}-\frac{(R-P)}{P}\right]$. This requires that the proportion of the contract price paid in advance equal half the difference between the buyer's and the seller's percent markups. If this condition is satisfied and 
if the buyer and seller are equally risk averse, then discharge would lead to economically efficient risk bearing. This situation seems very unlikely. Finally, suppose cases (1) or (2) apply. Then the risk minimizing damage remedy is $R-(1-a) P$, which can never equal zero. So a damage remedy of zero in this case can never satisfies the conditions for efficient risk bearing.

We have shown that efficient risk bearing requires a non-zero damage remedy except in some special cases. The special cases require that a relationship be satisfied between the buyer's and the seller's percent markups and the portion of the contract price that is paid in advance, where the exact relationship depends on the relative degree of risk aversion of the buyer versus the seller. We did not calculate the exact relationship, but we demonstrated it for two examples. ${ }^{17}$ These special cases do not seem to follow any normal business rule of thumb and therefore would not be expected to occur except by chance. Except in these special cases, a non-zero damage remedy is required for efficient risk bearing, so the discharge remedy cannot lead to an efficient outcome. Further, even in the special cases, zero damages cannot lead to efficient breach incentives, since a zero damage level never satisfies criterion (A).

What can be said concerning the degree of economic inefficiency resulting from discharging contracts in the various cases? We showed above that the damage remedies which are compatible with efficient risk bearing must fall within the range between $R-(1-a) P$ and $C-(1-a) P$. But the damage remedy which causes the seller to make an efficient decision concerning whether to perform the contract always equals $R-(1-a) P$, which must always be positive. Discharging a contract and excusing the seller from paying damages at all leads to the largest distortions when the value of the efficient penalty is highest, which makes the difference between the value of the efficient penalty and zero greatest. The efficient penalty itself is largest when the seller is risk neutral (cases (1) and (2)), when the seller has a high degree of influence over whether the contract can be performed or not, when all or most of the contract price has been paid in advance ( $a$ is near one), and when the buyer's profit when the contract is performed $(R-P)$ is high. Use of the discharge remedy leads to the smallest loss in economic efficiency when the seller has no control over whether performance occurs or not, when the seller is risk averse and the buyer is 
risk neutral (case (3)), when little or none of the contract price is paid in advance, and when the buyer's profit if the contract is performed is small. The distortion in economic incentives is intermediate in size when both parties are risk averse (case (4)).

We have shown that the discharge remedy in general satisfies neither efficiency criterion (A) nor (C). Discharging unperformed contracts neither allocates risk efficiently (except in some special cases), nor does it give promisors efficient incentives concerning when to perform or not to perform contracts. Thus judges should always treat cases involving nonperformance of contract as breach of contract cases. They should always levy damages on the non-performing party, where the best level of damages was shown to depend on the attitudes toward risk of the buyer and seller, on the amount of the contract price paid in advance, and on how important is the seller's control over whether the adverse event occurs. If best damage remedy appears to be negative, then the assumptions made concerning the parties' parties risk preferences are probably incorrect and the calculations should probably be redone using different assumptions. Occasionally, the best damage remedy will equal zero, but this outcome will occur only by chance.

Efficient damages when the seller has partially performed the contract or has partially fixed production costs

In the discussion above, we assumed that the seller's normal production costs were entirely composed of variable costs which would be saved in full if the cost increase occurred and the contract were not performed. But in many cases, the cost increase might not occur until several months after the contract was signed. Then the seller would probably not be able to save all her costs if the contract were not performed. This could be because some of the seller's costs are fixed and are incurred regardless of whether the contract is performed or not. Alternately, it could be because the seller has already partly performed the contract, but has not yet produced any useful output. As an example of fixed versus variable costs, suppose the contract is for supply of some specialized service such as catering. If the contract is not performed, then the caterer may save his food costs, but be idle himself. Then the saved food costs are variable costs, but the time of the caterer is a fixed cost. Alternately, the contract might be for supply of some complicated boat made to order. 
Suppose that at the time the adverse event occurs, the boat is half completed, but halffinished boats are worthless. Then the costs of labor and materials already expended are fixed costs, but labor and materials not yet used whose purchase can be cancelled are variable costs.

Suppose the seller's costs are partly fixed and partly variable. Fixed costs per unit are denoted $C_{f}$ and variable costs per unit $C_{v}$. Total costs, $C$, are now the sum of fixed plus variable costs, or $C=C_{f}+C_{v}$. When the unexpected event occurs, it raises the cost of completing the contract from $C_{v}$ to $C_{v}^{\prime}$. The damage remedies leading to efficient risk bearing can be computed by the same method as used above.

Cases (1) and (2). Both parties risk neutral or seller risk neutral and buyer risk averse. In this case the efficient damage remedy does not depend on the seller's costs, so it is unchanged from the situation already analyzed. The efficient damage remedy equals $R-$ $(1-a) P$.

Case (3). Seller risk averse and buyer risk neutral. In this case the seller incurs costs of $C_{f}$ per unit regardless of whether the contract is performed or not. Then the damage remedy which fully insures the seller when the contract is not performed is $C_{v}-(1-a) P$. Since the seller receives part of the contract price, $a P$, in advance and has already spent $C_{f}$, the seller's profit if the contract is not performed will be $a P-C_{f}-\left[C_{v}-(1-a) P\right]$. But this equals $P-C$, which is the same as the seller's profit if the contract is performed. This damage remedy is smaller than the damage remedy previously calculated for the case in which all costs were assumed to be variable. The larger the proportion of costs which are fixed, the smaller the efficient damage remedy becomes.

Note that the damage remedy leading to efficient risk bearing may again take on negative values, when $C_{v}<(1-a) P$. Negative values are more likely to occur when more of the seller's costs are fixed. But then, as indicated, above, we expect that the parties will specify a high value of $a$ in their contract. As above, the damage remedy leading to efficient risk bearing may also take on a zero value in special cases. For example, if the value of $a$ chosen by the buyer and seller equals $\left(P-C_{v}\right) / P$, then the damage remedy leading to efficient risk bearing is zero. Also if the seller's costs are entirely fixed and if the entire contract price has been paid in advance, or $C_{v}=0$ and $(1-a) P=0$, then the efficient damage remedy equals zero. 
$P$ and $R^{18}$ discuss an example of this latter situation. Suppose a farmer contracts in advance for sale of his crop. The crop fails because of drought and the seller does not perform the contract. Suppose also that the farmer has already incurred all his costs by the time of the drought. $P$ and $R$ argue that such cases should be discharged because farmers are risk averse with respect to weather, which can affect them severely because individual farms are gcographically concentrated, while buyers are risk neutral since they are dealers who buy over a larger geographical area. The analysis here would hold such contracts to be breached, but the efficient damage remedy could be zero if all of the farmer's costs were expended by the time of the drought $\left(C_{v}=0\right)$ and the entire contract price had been paid in advance $((1-a) P=0)$. This result would be the same as that advocated by $P$ and R. However, an alternative interpretation would be that the farmer chose to breach the contract by not using more irrigation water to offset the effect of lack of rainfall or by not purchasing extra grain on the market to offset his own shortfall. In this latter case, criterion (A) would be an issue and the efficient damage remedy should be positive and closer to $R$, in order to give the farmer efficient breach incentives.

Case (4). Both parties risk averse. Efficient risk bearing requires that the damage remedy be between $R-(1-a) P$ and $C_{v}-(1-a) P$ when production costs are partly fixed. A liquidated damage penalty equal to zero is again within the range of efficient penalties. But any remedy below the maximum of the range, $R-(1-a) P$, distorts the seller's decision concerning whether to perform the contract or not.

This section and the previous one suggest the range of damage penalties associated with efficient risk bearing. They also suggest what factors the courts need to focus on in deciding what the damage payment should be. In particular, whether the contract price was paid in advance, whether the seller's costs are fixed or variable, and the degree of control the seller has over the probability of the adverse event occurring all have an important effect on the efficient damage remedy when the seller is risk averse, cases (3) and (4). In general, efficient damage remedies are lower when more of the seller's costs are fixed rather than variable.

Are the damage remedies implied by efficient risk bearing ever the same as restitution damages? 
One question not yet considered is whether the damage remedies leading to efficient risk bearing might ever be the same as the restitution damage remedy, which requires that the seller return the amount paid in advance by the buyer when the contract is not performed. In our model, this would be equivalent to damages of $a P$.

The level of damages leading to efficient risk bearing in cases (1) and (2) is $R-(1-a) P$. Therefore, for the level of efficient damages to equal restitution damages, we must have $R-(1-a) P=a P$. This condition is only satisfied if $R=P$, which we assumed could not occur since it requires that the buyer make losses when the contract is performed. The equivalent condition in case (3) requires that $C_{v}-(1-a) P=a P$, assuming that at least some of the seller's costs are fixed. This condition is only satisfied if $C_{v}=P$, which we assumed could not occur since it requires that the seller make losses when the contract is performed, even when the adverse event does not occur.

Finally, in case (4), damages leading to efficient risk bearing are within the range given above. Suppose now that the buyer and seller are both equally risk averse and that they agree on a liquidated damage remedy at the midpoint of the efficient damage range, or $.5(R-(1-a) P)+.5(C-(1-a) P)$. For this to equal restitution damages requires that $a P=.5(R-(1-a) P)+.5(C-(1-a) P)$. But there is no value of $a$ which satisfies this expression. The only conditions under which the expression is satisfied are when $C=P$ and $R=P$, which we assumed cannot occur. Further, it is easy to show that the same result holds for any value of the liquidated damage remedy, i.e., for any degree of relative risk aversion on the part of the buyer versus the seller. ${ }^{19}$

Thus we have shown that the damage remedy which leads to efficient risk bearing can never equal the restitution damage remedy.

\section{Efficient Damage Remedies in Impossibility Cases}

In this section, I analyze the circumstances in several types of cases where contracts might be discharged based on the doctrines of impossibility, impracticability or frustration. The purpose here is both to indicate the applicability of the framework developed above and to explore briefly some newer areas in which discharge doctrines have been applied. 


\section{The coronation cases}

The "coronation cases" are frequently cited in connection with the development of doctrines relating to contract discharge. In these cases, lessees rented rooms from which to vicw the coronation procession of Edward VII, but the coronation was cancelled because Edward developed appendicitis. Relating these cases to the framework explored above, the rent payment would be $P$, the rent payment made in advance would be $a P$, and an individual lessee's total consumer surplus or willingness-to-pay from viewing the procession, including the amount paid in rent, would be $R$. ( $R$ could alternately be interpreted as the amount that the lessee could earn by selling seats in the rooms to others to view the procession.) The lessor's costs consist of lost rent from displacing normal tenants and expenditures to fix up the rooms for the coronation. These costs would be fixed if they were already incurred by the time the cancellation of the coronation was announced and would be variable otherwise. ${ }^{20}$ In the coronation cases, the issue of efficient incentives for performing the contract is irrelevant, since the lessors had no influence on whether the coronation took place or not. Also there were no significant reliance expenditures by the lessees, so $S=0$. Therefore the only economic efficiency issue is that of efficient risk bearing.

Focussing on risk bearing, the analysis of the previous sections suggests that the economically efficient damage remedy to be paid by the lessors (the sellers) should have been in the range between $R-(1-a) P$ and $C_{v}-(1-a), P$ depending on the risk preferences of the lessors and lessees.

Given the facts of the coronation cases, it seems unlikely that the lessors were providing insurance to the lessees. Suppose the lessees were fanatic royalists for whom a coronation is an "event of a lifetime." Then their total willingness-to-pay to view the procession might have been many times larger than the rent payment, particularly if there were many landlords competing among themselves to rent rooms with views. In these circumstances, it seems unlikely that the lessors would be providing full insurance against cancellation to the lessees, since full insurance would imply that the lessors agreed to pay very large penalties in the event of cancellation. What seems more likely is that the lessors were risk 
averse and the lessees risk neutral or that the risk was shared between the parties, as in cases (3) or (4).

The coronation cases provide an example of non-performance of contract cases in which the courts explicitly considered the issue of whether the contract price was paid in advance or not and also allowed for both positive and negative damages in different cases. In one case, Krell v. Henry, a part payment had been made in advance by the lessee. The court discharged the contract and did not require the lessor to return the advance payment. ${ }^{21}$ This outcome, which is equivalent to a zero damage remedy, could be efficient if both parties were risk averse, since the range of efficient penalties in the part-payment situation includes zero. In two other of the coronation cases, Chandler v. Webster, and Blakely v. Muller, ${ }^{22}$ the court required that the lessees pay the lessors the full amount of the: agreed-on rent even though full payment had not been made at the time the coronation was cancelled. This payment is equivalent to levying a negative damage remedy on the lessor, since the payment is made by the lessee to the lessor. It could also be within the range of economically efficient damage remedies if both parties were risk averse, since the range of efficient remedies includes negative penalties levied on the seller if no payment has been made in advance.

Efficient damage remedies when unexpected inflation occurs or prices rise in several markets at once

Now suppose the unexpected event which might occur changes several prices and/or costs at once. This might occur because the price and cost changes are due to generalized inflation which affects many prices in the economy. Or it might occur because prices in several markets are related.

Suppose again that when the price rise occurs, the cost of producing widgets rises from $C$ to $C^{\prime}$ and simultaneously the price of widgets in the market rises from $P$ to $P^{\prime}$. Also the price in the market on which the buyer re-sells rises from $R$ to $R^{\prime}$. If a generalized inflation causes these price changes, then all the increases would probably be in the same. proportion, i.e., $P(1+r)=P^{\prime}, R(1+r)=R^{\prime}$ and $C(1+r)=C^{\prime}$, where $r$ is the rate of inflation. But the price changes might alternately be at different rates without changing 
the example. $S$ is assumed to be a fixed cost already incurred by the buyer which is not affected by the price rise. ${ }^{23}$

An example of interrelated price changes would be the Suez Canal cases, a group of cases in which the closing of the Canal in 1956 caused litigation over which party would bear the extra costs of shipping goods around Africa. The Canal's closing also caused the prices of goods originating in India and East Africa, which were normally transported via the Canal, to rise in England and other destination countries. ${ }^{24}$ In the Suez Canal cases, the sellers were shipowners and the buyers were owners of cargo who purchased transport.

In the Suez Canal context, $C^{\prime}-C$ would be the extra cost per ton of shipping, say, groundnuts from Sudan to England via the Cape of Good Hope rather than via Suez. $P^{\prime}-P$ would be the increase in the price per ton of shipping via the Cape. $R^{\prime}-R$ would be the increase in the sale price per ton of groundnuts in England. ${ }^{25}$ The cost and price increases are expected to be interrelated here. The relationship between the increase in the cost of shipping per unit and the increase in the price of shipping per unit depends on the characteristics of the shipping industry. Assuming the industry to be fairly competitive, then ship owners would be expected to pass on the full increase in the cost of shipping to customers, but no more, so that $P^{\prime}-P$ would equal $C^{\prime}-C$. The price of groundnuts, $R^{\prime}-R$, would be expected to rise by less than the increase in the price of shipping per unit, $P^{\prime}-P$, as long as demand for groundnuts were somewhat elastic (i.e., not perfectly inelastic) or there were alternate sources of supply of groundnuts from countries which do not require the Suez Canal for shipping to England, such as Brazil.

Assume that the contract between the buyer and the seller contains no price adjustment provision, so that the contract price remains $\boldsymbol{P}$ when the Canal closes. The seller's profit is $P-C^{\prime}$ if the price rise occurs and the seller performs. Alternately, if the seller does not perform the original contract, she can resell the good (cargo space) on the open market for the higher price $P^{\prime}$ and transport new cargo at cost $C^{\prime}$. The seller's profit will then be $P^{\prime}+a P-C^{\prime}$ minus damages. The buyer's profit is $R-P-S$ if the price rise does not occur and the contract is performed. If the Canal closes and the contract is performed, the buyer's profit is $R^{\prime}-P-S$. If the seller does not perform when the Canal closes, I assume that the buyer covers by purchasing transport on a different ship for $P^{\prime}$ and can sell the groundnuts in England for $R^{\prime}$. His profit will then be $R^{\prime}-P^{\prime}-a P-S$ plus damages. 
In this situation, criterion (A) is irrelevant, since it is equally efficient for the seller to perform or not perform the contract once the Canal has closed. Note that the buyer's and the seller's profits together are $R^{\prime}-C^{\prime}-S$ if the contract is performed and are the same if the contract is not performed. The reason for this is that the value of output produced by the buyer and seller is the same regardless of whether the contract is performed or not. The only difference is whether they buy or sell transport for $\boldsymbol{P}$ or $\boldsymbol{P}^{\prime}$, which has offsetting benefits and costs to each of them and is therefore a distributional effect only. Thus the only economic consideration is that of efficient risk bearing.

Cases (1) and (2). Seller risk neutral and buyer risk averse or risk neutral. In this case, damages leading to efficient risk bearing must equalize the buyer's profit in the normal situation when the Canal remains open and in the abnormal situation when the Canal closes and the contract is not performed. The buyer's profit when the Suez Canal remains open is $R-P-S$. The buyer's profit when the Canal closes and the seller does not perform is $R^{\prime}-a P-P^{\prime}-S$ minus damages. To insure the buyer's profit regardless of whether the contract is performed or not requires that damages must equal $P^{\prime}-(1-a) P-\left(R^{\prime}-R\right)$, or the increase in the buyer's payment for shipping minus the increase in the buyer's revenue. Note that in the Suez Canal example, the efficient level of damages would always be positive, since we argued that $R^{\prime}-R$ would always be less than $P^{\prime}-P$.

One interesting feature of this case is that even the damage remedy just developed does not completely insure the buyer. With this damage remedy, the buyer makes a profit of $R-P-S$ if the Canal closes and the seller does not perform, but makes the higher profit of $R^{\prime}-P-S$ if the Canal closes and the seller does performs. No single damage remedy can provide the buyer with full insurance in all possible outcomes.

Case (3). Seller risk averse and buyer risk neutral. Here the efficient damage rcmedy must equalize the seller's profits regardless of whether the contract is performed or not. The seller's profit when the Canal remains open are $\boldsymbol{P}-C$. The seller's profit when the Canal closes and the seller does not perform is $a P+P^{\prime}-C^{\prime}$ minus damages. To insure the seller's profit regardless of whether the contract is performed or not requires that damages equal $\left(P^{\prime}-(1-a) P\right)-\left(C^{\prime}-C\right)$, or the increase in the buyer's payment for shipping minus 
the increase in the seller's production cost. ${ }^{1}$ In the Suez Canal example, I argued that $P^{\prime \prime}-P$ would approximately equal $C^{\prime}-C$. This means that the efficient damage remedy in case (3) must be positive as long as some advance payment on the contract price is made, i.e., $a$ exceeds zero.

Case (4). Both buyer and seller risk averse. In this case the damage remedy must be within the range between those in cases (1) and (2) and those in case (3).

The efficient damage remedies in the case of interrelated price changes can again equal zcro in special cases. These require that in risk cases (1) and (2), the level of advance payment chosen by the parties, $a_{3}$, satisfy the condition that $a_{3}=\frac{\left(R^{\prime}-R\right)-\left(P^{\prime}-P\right)}{P}$. In risk cases (3) and (4), the level of advance payment, $a_{4}$, must equal $\frac{\left(C^{\prime}-C\right)-\left(P^{\prime}-P\right)}{P}$. Both conditions require that the difference between the two price or cost increases, divided by the contract price, must equal the proportion of the contract price paid in advance. There would seem to be no reason to expect a relationship except by chance between the payment made in advance, the difference between two rates of price or cost increase, and the risk preferences of the buyer and seller. This is particularly so since the rates of price/cost increase become known only after the signing of the contract. Thus when interrelated price changes occur, again courts should treat non-performance of contract cases according to the doctrine of contract breach. In general, the level of damages required for both efficient risk bearing and efficient performance incentives is positive.

\section{Discharge in personal bankruptcy cases}

Theodore Eisenberg has pointed out the applicability of risk bearing considerations to the analysis of the bankruptcy discharge. ${ }^{26}$ Bankruptcy law allows non-corporate debtors who file for bankruptcy to be discharged from the obligation to repay their debts as long as they give up all assets owned over and above a specified exemption level which varies by state. Alternately, employed debtors can obtain a discharge from debt without giving up any assets by agreeing to pay creditors over three years an amount equal to the value

1 With this damage remedy, the seller makes a profit of $P-C$ if the Canal closes and the contract is not performed, but makes profit of $P-C^{\prime}$ if the Canal closes and the contract is performed. However, since $P-C^{\prime}<P-C$, the seller will always choose to perform and will therefore be insured. 
of their assets that would otherwise have to be given up. In bankruptcy, the debtor is the performing party and creditors are the non-performing parties. Applying the $\mathbf{P}$ and $R$ analysis of contract discharge to the bankruptcy situation, discharging debtors would be efficient if creditors were the superior risk bearers, or if debtors were risk averse and creditors were either risk neutral or less risk averse than debtors. It is often assumed that creditors are the superior risk bearers because their assets, which consist of loans to many individuals, are more diversified that those of borrowers.

However, bankruptcy is an example of a situation in which the performing party may have a great deal of influence over whether the adverse event leading to non-performance occurs or not. While some debtors file for bankruptcy because of events over which they have no control, such as a serious illness; others may borrow heavily, anticipating that if an adverse event such as becoming unemployed occurs, then the bankruptcy discharge will in effect provide them with insurance. In situations in which the debtor has full or partial control over the decision whether or not to perform the loan contract, discharging the debtor's liabilities in bankruptcy provides debtors with an incentive to borrow too much and to default too often. Thus discharging loan contracts in bankruptcy by allowing zero repayment is likely to generate inefficiency with respect to the debtor's incentive to perform the contract. ${ }^{27}$ Although the bankruptcy discharge can be argued to be good public policy because it provides debtors with a "fresh start," our analysis suggests that it would be economically efficient to require debtors filing for bankruptcy to pay damages to creditors, i.e., to require that debtors repay at least part of their debts. ${ }^{28}$

\section{Conclusion}

In this paper I have argued that the courts should treat all cases involving unperformed contracts as breach of contract cases rather than as discharge cases and that the nonperforming party should pay non-zero damages except in a few special cases. In other words, contracts should never be discharged. Rules for determining the economically efficient level of damages in different types of cases were developed and were shown to depend on such factors as the risk preferences of the contracting parties, the degrce of control or influence of the performing party on whether the event causing non-performance 
occurs or not, the relative level of the performing party's fixed versus variable production costs, the proportion of the contract price paid in advance, and whether the event causing non-performance affects a single cost item or is due to generalized inflation.

Efficient damage remedies were shown to be smallest when the performing party is risk averse and the non-performing party is risk neutral. They are largest when the performing party is risk neutral, regardless of the risk preferences of the non-performing party. Efficient damage remedies are largest when most or all of the contract price has been paid in advance, and smallest when little or none of the price has been paid in advance.

Both zero and negative damage levels were shown to occur in some situations. A zcro level of damages - the damage remedy when contract cases are discharged-leads to efficient risk bearing in some special cases, but these we showed to be rare and unlikely to occur very often. A zero damage level also has the disadvantage that it always leads to inefficiently high breach incentives on the part of the performing party. Negative levels of damage-which imply a payment by the buyer to the seller when the seller does not perform the contract - also can lead to efficient risk bearing in some cases. Negative damage remedies can occur when the seller is risk averse and the buyer is risk neutral or when the seller is more risk averse than the buyer. But the analysis showed that the damage remedy leading to efficient risk bearing varies with the proportion of the contract price paid in advance, for any risk preferences by the contracting parties. As more of the contract price is paid in advance, the efficient damage remedy always increases from a negative to a positive level. Whenever the performing party to a contract is truly more risk averse than the non-performing party, the performing party is likely to anticipate difficulties in collecting negative damages for non-performance, particularly if the performing party has any control over the performance decision. Therefore, if the seller is the performing party, the seller will insist on full or nearly full payment in advance. But when payment is made in advance, the damage remedy leading to efficient risk bearing is always positive, and discharging the contract is therefore inefficient. Thus the courts should always be sccptical of arguments that the contract should be discharged because the efficient damage remedy is zero or negative. Any performing party making this argument is likely to be misrepresenting its risk preferences. 
Thus in general, courts should treat cases involving non-performance of contract according to the doctrine of contract breach, rather than concentrating their efforts on deciding whether or not to discharge the contract. Except in rare cases, it is always economically efficient for the non-performing party to pay non-zero damages. 


\section{Footnotes}

*I am grateful to the Cook Fund of the University of Michigan Law School for research support and to Richard Epstein, Roger H. Gordon, Avery Katz, A. Mitchell Polinsky, Richard A. Posner, James J. White, and Ann D. Witte for helpful comments.

${ }^{1}$ See Steven Shavell, Damage Measures for Breach of Contract, 11 Bell Journal of Economics 466 (1980), which develops criteria (A) and (B), and A. Mitchell Polinsky, Risk Sharing Through Breach of Contract Remedies, XII Journal of Legal Studies 427 (1983), which develops criterion (C). Other related articles include Rea, Nonpecuniary Loss and Breach of Contract, 11 J. Legal Stud. 35 (1982), and Kornhauser, Breach of Contract in the Presence of Risk, Reliance and Reputation, 26 Journal of Law \& Economics 691 (1983).

${ }^{2}$ No one damage measure satisfies all three efficiency criteria simultaneously. This means that a choice between different damage remedies must sometimes be made on the basis of which of the three efficiency goals is most important. See Shavell, On the Design of Contracts and Remedies for Breach, XCIX Quarterly Journal of Economics 121 (1984), for discussion.

${ }^{3}$ Impossibility and Related Doctrines in Contract Law: An Economic Analysis, $6 \mathrm{~J}$. Legal Stud. 83 (1977).

${ }^{4} \mathrm{I}$ ignore criterion (B), efficient reliance by the buyer, here and in the rest of the paper.

${ }^{5}$ Thus neither party is ever a risk lover.

${ }^{6}$ The possibility that some of the seller's costs might be fixed is considered below.

${ }^{7}$ The amount $S$ is the buyer's reliance expenditure. The buyer may use the widgets to produce some final product or may just re-sell them. For simplicity, we assume the latter here.

${ }^{8}$ See section 4 below for an example in which the buyer covers when the seller does not perform.

${ }^{9}$ Supra note 1.

${ }^{10}$ From the viewpoint of efficient risk bearing, the efficient damage remedy actually is indeterminate, which is the result given by Polinsky, supra note 1. However, when risk bearing considerations are irrelevant, expectation damages are the best remedy because of 
their desireable effects on the seller's incentives concerning when to perform the contract--... efficiency criterion (A). This ignores criterion (B), efficient reliance, however.

${ }^{11}$ The contract price might rise in this case because the risk averse buyer is willing to pay more for the contract with the insurance. However if the widget industry is competitive and all widget sellers are risk neutral, then competition would prevent the price from rising since providing insurance does not cost the sellers anything.

${ }^{12}$ The contract price in this case might or might not be lower than $P$ in this case, since the seller would be willing to accept a lower price to avoid bearing risk, but competition among buyers might prevent the price from falling since buyers can provide insurance costlessly.

${ }^{13}$ Another way of putting this is that if both parties were risk averse, they would never agree between themselves on a liquidated damage penalty outside this range.

${ }^{14}$ Supra note 3 at $88,90-92$.

${ }^{15} \mathrm{P}$ and $\mathrm{R}$ recognize that in some cases, the performing party's actions may affect the probability that the adverse event which prevents performance will occur. They treat this as an indication that the performing party is the superior risk bearer. See $\mathbf{P}$ and $\mathrm{R}$, supra note 3 at 90 .

${ }^{16}$ Adjustments to the contract price that might occur depending on which party absorbs risk are ignored here and in the remainder of the paper.

${ }^{17}$ More generally, it requires that the portion of the contract price paid in advance fall as the buyer becomes more risk averse relative to the seller. Note that in the $a_{2}$ situation, the buyer is more risk averse relative to the seller than in the $a_{1}$ situation, and $a_{2}$ inust be less than $a_{1}$.

${ }^{18}$ Supra, note 3.

${ }^{19}$ Suppose the buyer and seller have unequal levels of risk aversion. They choose a liquidated damage remedy of $q(R-(1-a) P)+(1-q)(C-(1-a) P)$, where $q$ and $1-q$ are weights expressing the relative degree of risk aversion of the buyer versus the seller. Then the condition for the efficient damage remedy to equal restitution damages is that $q(R-(1-a) P)+(1-q)(C-(1-a) P)=a P$. But this equation implies that, $q(R-P)+(1-q)(C-P)=0$, which is only satisfied if $R=P$ and $C=P$. 
${ }^{20}$ In general, which costs are fixed versus variable depends on how much advance notice there is of the event causing non-performance. The more notice there is, the more costs are likely to be variable rather than fixed.

${ }^{21}$ [1903] 2 K.B. 740 (C.A.), discussed in Birmingham, A Second Look at the Suez Canal Cascs: Excuse for Nonperformance of Contractual Obligations in the Light of Economic Theory, 20 Hastings L.J. 1399 (1969).

${ }^{22} 88$ L.T.R. (N.S.) 90 (K.B. 1903) and [1904] 1 K.B. 493 (C.A.), discussed in Birmingham, supra note 21.

${ }^{23}$ If generalized inflation caused the price changes, then the real value of $P^{\prime}, R^{\prime}$, and $C^{\prime}$ would be the same as that of $P, R$, and $C$. See Schwartz, Sales Law and Inflations, 50 So. Cal. L. Rev. 1 (1976), for discussion of other contract cases in which unanticipated inflation was the event causing non-performance.

${ }^{24}$ See Birmingham, supra note 22, for discussion of these cases.

${ }^{25}$ These facts reflect one of the Suez canal cases, Albert D. Gaon \& Company v. Societe Interprofessionelle des Oleagineux Fluides Alimentaires, [1960] 2 Q.B. 334 (1959), aff'd, [1960] 2 Q.B. 348 (C.A.), discussed in Birmingham, supra note 22.

${ }^{26}$ Bankruptcy Law in Perspective, 28 U.C.L.A. L. Rev. 953 (1981), at 981.

${ }^{27}$ Eisenberg also argues that most bankruptcies do not fit the $\mathbf{P}$ and $\mathbf{R}$ criterion for discharge, both because the debtor can affect the probability of default and because the debtor is the superior risk bearer with respect to his own debts. Eisenberg, supra note 24, at $981-983$.

${ }^{28}$ See White, Personal Bankruptcy Under the 1978 Bankruptcy Code: Economic Considerations, 63 Indiana Law Journal, 1987, for discussion. 


\section{Recent CREST Working Papers}

87-1: Jeffrey K. MacKie-Mason, "Nonlinear Taxation of Risky Assets and Investment, With Application to Mining" September, 1984.

87-2: Jeffrey K. MacKie-Mason, "Sequential Decision Problems and Asymmetric Information" September, 1985.

87-3: Michelle J. White, "Contract Breach and Contract Discharge due to Impossibility: A Unified Theory" July $29,1987$.

87-4: Ted Bergstrom, "Systems of Benevolent Utility Interdependence" May 19, 1987.

87-5: Ted Bergstrom, "A Fresh Look at the Rotten Kid Theorem-and Other Household Mysteries" November, 1986.

87-6: Michelle J. White, "The Corporate Bankruptcy Decision” July, 1987.

87-7: Michelle J. White, "Location Choice and Commuting Behavior in Cities with Decentralized Employment" July, 1987.

87-8: Lawrence E. Blume and David Easley, "Implementation of Walrasian Expectations Equilibria" December, 1985.

87-9: Lawrence E. Blume, "Lexiocographic Refinements of Nash Equilibrium" April, 1986.

87-10: David Lam, "Lorenz Curves, Inequality, and Social Welfare Under Changing Population Composition" June 16, 1987.

87-11: Mark Bagnoli and Naveen Khanna, "Equilibrium with Debt and Equity Financing of New Projects: Why More Equity Financing Occurs When Stock Prices are High" June, 1987.

87-12: Mark Bagnoli and Barton L. Lipman, "Provision of Public Goods: Fully Implementing the Core through Private Contributions" March, 1987.

87-13: Mark Bagnoli and Barton L. Lipman, "Successful Takeovers without Exclusion" August, 1987.

87-14: Mark Bagnoli and Michael McKee, "Controlling the Game: Political Sponsors and Bureaus" May, 1987.

87-15: Mark Bagnoli and Michael McKee, "Can the Private Provision of Public Goods be Efficient?-Some Experimental Evidence" March, 1987.

87-16: Mark Bagnoli, "Non-Market Clearing Prices in a Dynamic Oligopoly with Incomplete Information" January, 1986.

87-17: John Laitner, "Bequests, Gifts, and Social Security" February 28, 1986.

87-18: John Laitner, "Dynamic Determinacy and the Existence of Sunspot Equilibria" May 12, 1986.

87-19: David Lam, "Does a Uniform Age Distribution Minimize Lifetime Wages?” August 12, 1987.

87-20: David Lam, "Assortative Mating with Household Public Goods" April, 1987.

87-21: Jeffrey A. Miron and Stephen P. Zeldes, "Production, Sales, and the Change in Inventories: An Identity that Doesn't Add Up" June 1987.

87-22: Jeffrey A. Miron and Stephen P. Zeldes, "Seasonality, Cost Shocks, and the Production Smoothing Model of Inventories" December, 1986.

87-23: Hal R. Varian, "Differencès of Opinion in Financial Markets" March, 1985.

87-24: Roger H. Gordon and Hal R. Varian, "Taxation of Asset Income in the Presence of a World Securities Market" August, 1986. 
87-25: Hal R. Varian, "Measuring the Deadweight Costs of DUP and Rent Seeking Activities" November, 1982.

87-26: Hal R. Varian, "Price Discrimination" January, 1987.

87-27: Roger H. Gordon and Hal R. Varian, "Intergenerational Risk Sharing" October, 1985.

87-28: Hal R. Varian, "Three Papers on Revealed Preference” August, 1987.

87-29: Hal R. Varian, "Optimal Tariffs and Financial Assets" April, 1987.

87-30: Jonathan Cave and Stephen W. Salant, "Cartels That Vote: Agricultural Marketing Boards and Induced Voting Behavior" August, 1987.

87-31: Stephen W. Salant and Donald H. Negri, "Pastures of Plenty: When is the Standard Analysis of Common Property Extraction Under Free Access Incorrect?" July 10, 1987.

87-32: Stephen W. Salant, "When is Inducing Self-Selection Sub- optimal for a Monopolist?" February, 1987.

87-33: Stephen W. Salant, "Treble Damage Awards in Private Lawsuits for Price-Fixing" August, 1987.

87-34: Stephen W. Salant and Roy Danchick, "Air Force Academy Attrition: A New Perspective on the College Dropout Problem" August, 1987.

87-35: Stephen W. Salant and Eban Goodstein, "Committee Voting Under Alternative Procedures and Preferences: An Experimental Analysis" April 20, 1987.

87-36: Robert B. Barsky and Jeffrey A. Miron, "The Seasonal Cycle and the Business Cycle" June, 1987.

87-37: Robert B. Barsky, N. Gregory Mankiw, Jeffrey A. Miron and David N. Weil, "The Worldwide Change in the Behavior of Interest Rates and Prices in 1914" July, 1987.

87-38: Jeffrey K. MacKie-Mason, “Taxes, Information and Corporate Financing Choices" April 1986. 


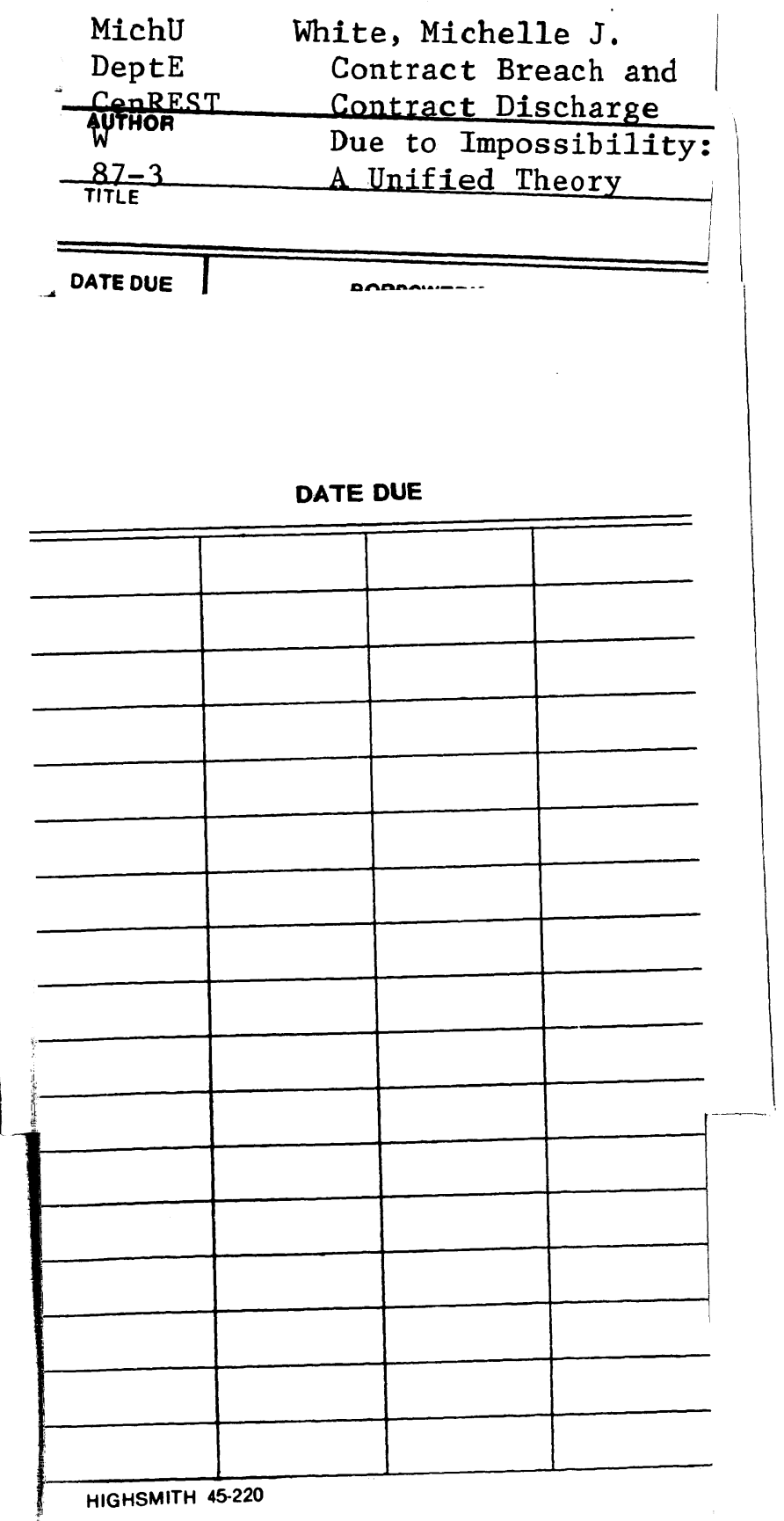
